\title{
EDITORIAL
}

\section{The European Respiratory Journal has a new coat}

With this issue, and with a new appearance, the European Respiratory Journal begins its tenth year of publication. Hopefully, this will be as successful as the previous ones which were characterized by a steady growth. The number of submitted manuscripts reached 1024 in 1995, and will be even higher in 1996. The manuscripts arrived from all over the world, most of them from the UK, followed by France, Japan, and Italy. The acceptance rate remained around $40 \%$, except for case reports with only $30 \%$ accepted in 1995 . Despite the increase of published pages to around 230 per issue in 1996, there was no compromise in the scientific quality of the published material, as evidenced in the rise of the impact factor to 2.3 in 1995 (after 2.1 in 1994 and 2.0 in 1993) which puts us second place amongst the journals on general respiratory medicine.

Having now more than 30 original articles to publish each issue, we felt the need for subheadings in the table of contents for the various topics, in order to facilitate the reader's accesss to articles of interest. Also, highlighted articles will appear on the front of each issue, starting with this volume. This required a change in the layout and graphic design of the cover. The familiar coat of the European Respiratory Journal, with the large bold name of the Journal and the logo of the European Respiratory Journal in red colour on a light blue background, has disappeared. The new cover keeps the colours red and light blue, to follow the "tradition". The layout had to be changed to create place for the titles of the highlighted articles. Our Management Board which approved the new design and was quite pleased with it, is now waiting for your reactions, and any comments to the Chief Editor are welcome.

Finally, last but not least, we want to thank the leaving Associate Editors for their excellent work: V. Brusasco, J.F. Cordier, C.H. Marquette, D.S. Postma, P. Richardson, A. Rossi, G.P. Semenzato, S. Sörenson, R.A. Stockley, A. Torres, A. Woolcock, and the two statistical editors L. Kaufman and J.P. Schouten. In addition, Leo Fabbri has decided to resign as Chief Editor of the European Respiratory Review and the Monograph, which developed so well under his creative and dynamic leadership. Thank you, Leo, for your efforts! We welcome the new Chief Editors, J. Bousquet for the Review and A. Rossi for the Monograph, and wish them good luck in their new activities. In the Sheffield Office, our Senior Scientific Technical Editor, Celia Emery, decided to resign from her post and to take the challenge of returning to a full time research position at the University of Sheffield. Her meticulous and creative work improved the text, figures and tables of many articles, and added to the high standard the European Respiratory Journal has achieved in this field.

We hope that with the continued support of authors and readers we will further enhance our reputation as a scientific journal of international standing.

\section{Ulrich Costabel \\ Chief Editor}

